\title{
ANA DE SAN BARTOLOMÉ: TRAS LA ESTELA TERESIANA \\ ANA DE SAN BARTOLOMÉ: AFTER THE TERESIAN WAKE
}

\author{
Ma José Rodríguez MosQuera \\ Universidad de Barcelona
}

\section{ResUmen}

Este artículo pretende analizar las estrategias discursivas de la discípula de Santa Teresa de Jesús: la Beata Ana de San Bartolomé. Siguiendo la estela teresiana, San Bartolomé, con una prosa humilde, sencilla y personal logró persuadir, ignorar e incluso desafiar a la autoridad masculina.

Palabras claves: Literatura, Santa Teresa de Jesús, Ana de San Bartolomé, siglo XVI, mística

ABSTRACT:

This paper aims to analyzes the discursive strategies the disciple of St. Teresa de Jesús: blessed Ana de San Bartolomé. Following the wake Teresa, San Bartolomé, with a humble, simple and personal prose manages to persuade, ignore and even challenge male authority.

KeY WORDS: Literature, St. Teresa de Jesús, Ana de San Bartolomé, century xVI, mystical

\section{INTRODUCCIÓN}

Ana García Manzanas, más conocida como Ana de San Bartolomé, nació en 1549 en Almendral de la Cañada (Toledo) y falleció en 1626 en la ciudad de Amberes. Fue la sexta hija de Hernán García y María Manzanas, quienes cimentaron su profunda devoción por la vida religiosa. Por eso, en junio de 1570, tras haber tenido en su infancia una visión de la Virgen, ingresó en el convento de San José de Ávila, cuna del Carmelo Descalzo, convirtiéndose así en la primera hermana de velo blanco, freila o lega que Teresa admitió en su Carmelo recién fundado. Meses después, ambas se conocieron personalmente y, a partir de entonces, surgió una relación especial que las unió hasta 
el final de la vida de la fundadora; y también tras su muerte, porque García Manzanas siempre la tuvo muy presente en sus escritos, hasta tal punto que Santa Teresa llegó a tener la misma importancia que Dios en su piedad y se erigió como una autoridad en su vida y en su obra, de ahí que, como se refleja en sus textos, la citase como a un ser divino que le permitía escribir, con un estilo sobrio y natural, sus vivencias místicas ${ }^{1}$.

El presente artículo desea analizar las estrategias discursivas que empleó, siguiendo a la santa abulense, Ana de San Bartolomé, y cómo logró, gracias a una prosa sencilla y llana, convencer, relegar y retar a la jerarquía masculina. Para llevar a cabo este objetivo se tiene en cuenta la obra editada de la autora, ya que la finalidad no es develar fuentes nuevas sobre la beata, sino proponer una síntesis interpretativa a través de su obra publicada.

\section{La hija PRedilecta de Teresa de Jesús}

Ana fue considerada la hija predilecta de Teresa y siguió sus pasos para convertirse en monja andariega; y también colaboró en la fundación de los últimos cuatro Carmelos: Villanueva de la Jara en Cuenca (1580), Palencia (1580), Soria (1581) y Burgos (1582). Además de compañera de viaje, enfermera, confidente, consejera y leal amiga, Ana se convirtió en la secretaria de la Santa carmelita, encargándose de redactar sus escritos. Teresa de Ávila, en una carta al P. Jerónimo Gracián fechada el 4 de diciembre de 1581, dejaba clara la labor de copista de la joven beata: «Ana de San Bartolomé no cesa de escribir, harto me ayuda»².

En 1604, San Bartolomé, junto con la carmelita homónima Ana de Jesús, y por petición de los delegados franceses, encabezó la marcha para implantar el Carmelo Teresiano en París. El 18 de octubre de ese mismo año, fundaron el Carmelo de la Encarnación - cuya priora fue Ana de Jesús - y, en enero de 1605, el de la villa de Pontoise, del que Ana fue nombrada priora, pero pronto tuvo que abandonarlo para ocuparse del Carmelo de París. Su estancia en la capital francesa estuvo cargada de obstáculos, debido a las desavenencias con el superior Pierre Bérulle, que desembocaron en un periodo de tristeza, de noche oscura ${ }^{3}$, que la llevó a componer, al estilo de Santa

\footnotetext{
${ }^{1}$ Véase el interesante artículo de M. Alcalá, «Escribir desde los márgenes: la escritura como milagro en las Vidas de monjas», eHumanista: Journal of Iberian Studies, 29 (2015), pp. 639-659.

${ }^{2}$ S. T. de Jesús, Obras completas, Efren De la Madre de Dios y Otger Steggink (eds.), Madrid, Biblioteca de Autores Cristianos, 2015, p. 1365.

${ }^{3}$ Este sentimiento de tristeza, angustia, confusión y soledad que refleja Ana de San Bartolomé, lo encontramos en el poema Noche de Juan de la Cruz cuyo primer verso reza «En una noche escura». Según indica Dámaso Alonso en La poesía de San Juan de la Cruz (desde esta ladera), Madrid, Aguilar, 1958, p. 59, la composición Noche refleja -igual que percibimos en el poema de Ana de San Bartolomé- una honda negación y esquivamiento de todo lo sensible y todo lo espiritual, con la sola guía de la luz de la $\mathrm{Fe}$, luz absoluta, total, y por total y absoluta, equivalente para el entendimiento humano a la más
} 
Teresa, dos emotivos poemas": uno, de 76 versos en el que clama a su señor y cuyo primer verso reza «Si ves mi pastor» ${ }^{5}$ y otro, de 8 versos en el que dialoga con Él y que comienza «iOh, dulce Jesús» ${ }^{6}$. En ambos poemas queda plasmado, por un lado, el

profunda oscuridad. Asimismo, es interesante la interpretación que ofrece sobre el poema de la Noche Domingo Ynduráin en la edición Poesía de San Juan de la Cruz, Madrid, Cátedra, 2004, pp. 215-217.

${ }^{4}$ Las dos composiciones que se mencionan y reproducen aquí están tomadas de la edición: A. de San Bartolomé, Obras completas, Julián Urkiza (ed.), Burgos, Monte Carmelo, 1999, pp. 756-759 y 761. A lo largo del artículo citaremos siempre esta edición porque compila de manera rigurosa el legado de la autora.

${ }^{5}$ [II]

Si ves mi pastor, háblale, Llorente, dile mi dolor, mira si lo siente.

Dilo con cuidado y bien dicho, pastor, que por qué ha cerrado así mi corazón, y siendo él el Señor así se me ausente.

Dile mi dolor, mira si lo siente.

Vuélveme la luz, caro y buen amigo, $\mathrm{y}$ venga la cruz como seáis servido, que ese es el camino que pide el amor.

Dile mi dolor, mira si lo siente.

La noche es oscura y da grandes temores, y los robadores que no se cunduran y entonces te escondes, mi buen fiador.
Dile mi dolor, mira si lo siente.

No os mostréis tan duro, 5 buena está la prueba y basta la hecha; pues veis no es seguro en tan flaca tierra $\mathrm{y} \tan \sin$ vigor.

Dile mi dolor, mira si lo siente.

¿Cómo me has metido en tan fuerte breña $y$ te has escondido dejándome en ella, y en una estrecha senda sin saber dónde voy?

Dile mi dolor, mira si lo siente.

Y si me ha entendido, ¿cómo no respondes a un triste suspiro que es cierto le oyes? Y eso más me pone triste y con temor.
Dile mi dolor, mira si lo siente.

Dile cuál estoy

$30 \mathrm{y}$ todas mis penas, $\mathrm{y}$ con gran dolor 55 de ver sus ausencias, $y$ en tierras ajenas, que es más el temor.

35 Dile mi dolor, mira si lo siente.

Dile que no tarde, porque yo me muero y no hallo nadie que me dé consuelo,

40 si yo no le veo en mi corazón.

Dile mi dolor, mira si lo siente.

Dile que a qué hora quiere que le aguarde, que él mismo la escoja y que me lo mande, y que yo le halle como a mi pastor.

50 Dile mi dolor, mira si lo siente.

El verso 24 es de difícil interpretación. Ni en el Diccionario de Autoridades, ni en el Diccionario de la Real Academia Española se ha podido esclarecer el significado del verbo «cundurar». Ahora bien, en el DRAE sí figura el verbo «condurar» con el significado de «hacer durar algo o economizarlo», que puede corresponder al sentido del verso.

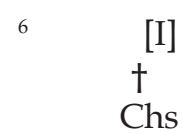

¡Oh, dulce Jesús,

nuestro bien y gozo!

Dadme vuestra luz,

mírenme tus ojos.

Jesús me miró

y yo le miré.

Díjome: «Yo, yo

por ti moriré».

Algunas de sus composiciones están encabezadas por el anagrama chs precedido de una cruz en la parte 
entusiasmo, la espontaneidad y la humildad de su autora, y, por otro lado, el escaso valor estilístico, que se percibe en su tono sencillo y en sus rimas y versos irregulares, que distan de la musicalidad del modelo literario del momento ${ }^{7}$.

Tras años dificultosos en Francia, la religiosa partió camino de Flandes para fundar en la ciudad de Amberes su último Carmelo. En esta ciudad transcurrirán los últimos años de su vida y será donde se forjará como escritora, y llevará a cabo la mayor parte de sus composiciones, casi todas ellas de carácter autobiográfico.

\section{Obra de Ana de San Bartolomé}

Los documentos que se conservan relativos a la figura de Ana de San Bartolomé pueden dividirse en cuatro grupos ${ }^{8}$ :

a. Escritos histórico-autobiográficos, en los que se recogen relatos sobre Santa Teresa (por ello se la considera una fuente relevante para conocer mejor a Teresa de Jesús): Últimos años de la madre Teresa de Jesús, Declaración sobre la traslación del cuerpo de la madre Teresa de Jesús: 1587 y Declaración en el proceso de beatificación de la madre Teresa de Jesús: 1598; el inicio del Carmelo teresiano, Noticias sobre los comienzos del Carmelo Teresiano; el estado espiritual y psicológico antes de su viaje a la capital francesa, Disposición de su espíritu en vísperas de su viaje a Francia; sus experiencias místicas en Francia, Relaciones de conciencia (Pontoise: 1605); sus situaciones desagradables con Pierre de Bérulle, Relaciones de su estancia en París; el viaje de las carmelitas Descalzas de España a Francia y las primeras fundaciones en el país vecino, Noticias sobre los orígenes del Carmelo Teresiano en Francia; su vida mística, Diálogos sobre su espíritu; dos autobiografías en Flandes, Autobiografía de Amberes y Autobiografía de Bolonia, y una narración que lleva a cabo al final de su vida y en la que se muestra valedora de la santa abulense, Defensa de la herencia teresiana 9 .

b. El segundo grupo incluye escritos doctrinales, que reúnen conferencias en Francia y en Flandes - Conferencias espirituales (Pontoise: C. julio de 1605),

superior (†) que significa Cristo o Jesús.

${ }^{7}$ Para entender con mayor detalle la poesía de Ana de San Bartolomé, consúltese el trabajo de A. Prieto, La poesía española del siglo XVI, Madrid, Cátedra, 1998, Vol. II, pp.746-747. Asimismo, para un panorama más completo de la poesía femenina de los siglos XVI y XVII, véase J. Olivares, y E. S. Boyce, Tras el espejo la musa escribe. Lírica femenina de los Siglos de Oro, Madrid, Siglo XXI, 2012, pp.15-94.

${ }^{8}$ Para profundizar y conocer con mayor detalle cada uno de los escritos de Ana de San Bartolomé se recomienda consultar la edición citada anteriormente: A. de San Bartolomé, ob. cit., pp.18-24.

${ }^{9}$ Para consultar estos textos, véase A. de San Bartolomé, ob. cit., pp. 43-584. 
Conferencias espirituales (París: 1606-1608), Conferencias espirituales (Amberes: 1622-1624) y Conferencias espirituales (Amberes: 1621-1623) -; meditaciones sobre diferentes virtudes, Meditaciones sobre el camino de Cristo, y educación y enseñanza de las religiosas, Formación de novicias y ejercicios de piedad ${ }^{10}$.

c. El tercer grupo son los escritos poéticos, en los que se compila un total de quince poesías en las que predomina un estilo entusiasta y apasionado que recuerda al de Santa Teresa. Siguiendo la clasificación que ofrece Urkiza, podemos catalogar estas composiciones en tres apartados: poesías líricas («Si ves mi pastor», «¡Dios mío y mi Señor», «iOh dulce Jesús», «Quién llama con tal porfía» y «Levántate, Bras»), poesías didáctico-festivas («Levantaos, que viene el día», «Despertad de vuestro sueño», «¡Oh Niño, qué amor tenéis!», «Niño, Niño dónde vas», «El amor busca la cruz», «De cruz nos vino la vida») y poesías sobre acontecimientos de la vida religiosa («Zagalas, y ¿qué buscáis?», «¿Dónde vas con tanta gala?», «Dos palomas vuelan hoy», «Lleguéme a par de este río» ${ }^{11}$.

d. Y, por último, los escritos epistolares, formados por un total de 665 cartas conservadas que intercambió con sujetos de diferente índole: desde personas anónimas hasta aristócratas, y en las que se refleja la naturalidad, el carácter alegre y la generosidad humana que caracterizó a la emisora ${ }^{12}$.

Ella misma afirmaba en una carta - de noviembre-diciembre de 1625- a la madre Catalina de Bautista que su deseo de escribir provenía del ejemplo de su maestra, quien quiso comunicarse por escrito para ayudar a los devotos y enriquecer la convivencia entre las religiosas de sus palomares - así llamaba a los conventos -:

para animaros y andar en caridad unas con otras, que esto dijo una vez nuestra Santa diciéndola una madre Priora para qué escribía tanto a las monjas, que se cansaba, y dijo: «Porque deseo que vosotras lo hagáis y os comuniquéis las unas con las otras para que no se enfríe la caridad $»^{13}$.

\section{El magisterio autorizador de Santa Teresa de Jesús}

La vida y la labor de Ana como escritora tendrán como referente a Teresa de Jesús. García Manzanas también experimentará una existencia marcada por la

\footnotetext{
${ }^{10}$ Los diferentes textos de este apartado pueden leerse en A. de San Bartolomé, ob. cit., pp. 587-751.

${ }^{11}$ Las composiciones poéticas se encuentran en A. de San Bartolomé, ob. cit., pp. 755-784.

${ }^{12}$ En este caso, debido a la ingente cantidad de cartas, no reproducimos los títulos que conforman el apartado como en los grupos anteriores. Para conocer el contenido de dichas misivas, véase A. de San Bartolomé, ob. cit., pp. 787-1618.

${ }^{13}$ A. de San Bartolomé, ob. cit., p. 1586.
} 
enfermedad y el sacrificio del cuerpo, la lucha contra la tentación y la madurez en el encuentro con Dios ${ }^{14}$. Si Teresa de Ávila renace a una vida plena tras la lectura reveladora de las Confesiones de San Agustín, Ana explicará en su texto autobiográfico - Autobiografía de Amberes - cómo Dios escuchará sus plegarias y le dirá: «Yo haré lo que me pides; tendrás en qué padecer en compañía de mi amiga Teresa; los pasaréis las dos por los caminos» ${ }^{15}$. Su vida, entonces, vendrá marcada por el carisma de Teresa. Como apunta Alison Weber ${ }^{16}$, Ana de San Bartolomé creyó ciegamente «que ella era el vehículo a través del cual se transmitía el legado espiritual e histórico de santa Teresa». Precisamente, ella contará que la Santa le había donado de manera sobrenatural la capacidad de escritura -incluso empleará una caligrafía similar a la de su maestra - ${ }^{17}$; es decir, escribir fue para Ana un regalo cuyo objetivo fundamental era preservar y extender las enseñanzas de Teresa de Jesús ${ }^{18}$.

Beatriz Ferrús ${ }^{19}$ considera a Ana como figura de ventriloquía por la que habla la propia Teresa, quien está presente en gran parte de su escritura y llega a sustituir, en ocasiones, a Cristo. Leemos en el libro autobiográfico de la discípula cómo Santa Teresa se convirtió en un referente espiritual que llegó a ocupar el lugar de Dios:

Y estando la Priora para decir el oficio, vi la Santa sobre su silla con tanto resplandor, diciendo lo mismo que la prelada; y halléme toda mi alma inflamada en el amor de Dios, que todos los maitines lo tuve, muy agradecida de ver la gloria que tenía la Santa [...]. Otras veces muchas, me confortaba con un amor y un olor como si su santo cuerpo estuviera a la par de mí; y aunque no se mostraba, sentía su olor y favor que estaba cerca de $\mathrm{mí}^{20}$.

En todo caso, los escritos de la beata son un claro - y extremado - ejemplo de literatura de tradición teresiana, porque la Santa ejerció de guía tanto para Ana de San Bartolomé como para otras religiosas que la consideraron un modelo autorizador de escritora espiritual. La beata toledana narró su perfeccionamiento espiritual teniendo muy en cuenta las directrices de los superiores — «hago esto que me lo manda la santa obediencia ${ }^{21} \gg-$ pero, ante todo, considerando el beneplácito de su maestra ya fallecida

\footnotetext{
${ }^{14}$ B. Ferrús, «Crea que andamos hechizadas la una con la otra. Mujeres en el entorno de Santa Teresa (cuerpos y almas)», Scriptura, 19/20 (2008), p. 68.

${ }^{15}$ A. de San Bartolomé, ob. cit., p. 343.

${ }^{16}$ A. Weber, «El feminismo parcial de Ana de San Bartolomé», en L. Vollendorf, Literatura y feminismo en España (s. XV-XXI), Barcelona, Icaria, 2005, p. 79.

${ }^{17}$ Véase al respecto el artículo de A. Castillo, «Cartas desde el convento. Modelos epistolares femeninos en la España de la Contrarreforma», Cuadernos de Historia Moderna, 2014, Anejo XIII, pp. 141-168.

${ }^{18}$ Ver N. Baranda, Cortejo a lo prohibido. Lectoras y escritoras en la España moderna, Madrid, Arco/Libros, 2005, pp. 74-75.

${ }^{19}$ B. Ferrús, ob. cit., p. 67.

${ }^{20}$ A. de San Bartolomé, ob. cit., pp. 358-359.

${ }^{21}$ A. de San Bartolomé, ob. cit., p. 325.
} 
y, en último término, al que consideró su preceptor y director espiritual: Cristo, que es quien le encargó la tarea de convertirse en monja y quien, de alguna manera, reafirmó su función y sentido en el mundo.

\section{INTENCIÓN DE SUS ESCRITOS}

Ana deseó comunicarse abierta y sencillamente con sus lectores, para ayudarlos en su camino interior o para relatar hechos de la vida cotidiana de sus religiosas, como la feliz llegada de novicias. No solo escribió para consumo interno del convento, como muchas otras hermanas, sino que lo hizo pensando en el mundo que había más allá de los muros carmelitas, como en su momento hizo su referente vital, Teresa de Jesús. De esta manera, llegó a crear una red de comunicación, que cruzó toda España y parte de Europa gracias a la fundación de nuevos Carmelos en el extranjero.

San Bartolomé, del mismo modo que la santa abulense y otras monjas de la Contrarreforma europea, fue la autora de un relato de su vida religiosa. El género de la autobiografía espiritual femenina solía responder a la petición de un confesor o consejero espiritual con el fin de juzgar la ortodoxia de las experiencias espirituales de las monjas, de ahí que, raras veces fuera un ejercicio de expresión creativa. A la hora de narrar su experiencia espiritual, las monjas de la época sufrían, en palabras de Alison Weber, «ansiedad de autoría», porque tenían que autoconvencerse de que al redactar no sucumbían a la tentación de la vanidad y, por lo tanto, no podían traspasar la sutil línea divisoria que separaba el registro de sus experiencias y la confesión de las mismas, aunque la petición del confesor de escribir podía funcionar también como una licencia literaria, la «vida por mandato» ${ }^{22}$, de la que nuestra beata rehuía apoyándose en la creencia de que ella solo llevaba a cabo esta labor si se lo mandaba Cristo o Teresa de Jesús ${ }^{23}$.

Asimismo, Ana de San Bartolomé parecía estar libre de la denominada «ansiedad de autoría» porque no sentía que transgredía los límites de sus vivencias, sino que ella estaba convencida de que era el vehículo a través del cual se transmitía el legado espiritual e histórico de Santa Teresa, ya que consideraba que su capacidad para transcribir sus experiencias espirituales era un don sobrenatural transmitido por su madre carmelita ${ }^{24}$ quien, según Ana, tenía la misma importancia que Cristo, de ahí que la beata en sus escritos la mencione como un ser capaz de resolver sus conflictos interiores: «Encomendábame a ella y rezábala alguna cosa [...]. Y esta noche, estando

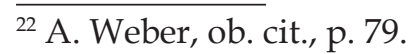

${ }^{23}$ Véase al respecto el trabajo de J. S. Amelang, «Autobiografías femeninas», en I. Morant (dir), Historia de las mujeres en España y América, Madrid, Cátedra, 2005, Vol. II, pp. 155-168.

${ }^{24}$ A. Weber, ob. cit., p. 79.
} 
media dormida se me apareció resplandeciente como un sol y díjome: "Pídeme lo que quisieres, que yo te lo alcanzaré", y desapareció» ${ }^{25}$.

En su primera autobiografía, compilada en Autobiografía de Amberes ${ }^{26}$, que comenzó a hilvanar hacia 1607, Santa Teresa está siempre muy presente como autoridad mística y referencia literaria porque le permite proclamar el valor espiritual propio al mismo tiempo que demostrar su humildad. Gracias a ella, Ana, resuelve de una forma más fácil el conflicto entre la autoridad del confesor y su experiencia interior, pues, cuando este le indica que sus impulsos espirituales son a consecuencia del demonio, ella escribe:

Yo fui a nuestra Santa que me dijese si era así, y dila cuenta de todo lo que me había pasado. Y díjome que no tuviese pena, que no era demonio, que ella había pasado por esa misma oración, con los confesores que no la entendían. Con esto yo quedé consolada y creí que lo que la Santa me decía era Dios ${ }^{27}$.

Vemos cómo lo que suponía una importante fuente de angustia para Santa Teresa en su autobiografía queda pronto resuelto en la confesión de Ana, quien no siente la necesidad u obligación de someter sus visiones y favores espirituales a la revisión de los confesores porque ya había recibido la aprobación de la Santa ${ }^{28}$. Es significativo que el confesor como destinatario esté ausente en su autobiografía, ya que comienza: «María, José y nuestra santa madre Teresa de Jesús, en cuyo nombre hago esto que me lo manda la santa obediencia ${ }^{29}$. Esta omisión del confesor como destinatario demuestra que Santa Teresa es quien realmente representa la autoridad y es la única capaz de resolver sus conflictos espirituales.

Ana de San Bartolomé fue capaz, como bien ha demostrado Alison Weber, de desafiar la jerarquía de la relación discursiva confesor-penitente como vemos en una carta que escribió a su confesor Pierre de Bérulle a quien, amablemente le rechazó su petición de escribir un relato espiritual:

En lo que v.m. me manda que le escriba de mi interior, suplico a v.m. me perdone y no me lo mande. Y no lo tenga por desobediencia, que de verdad no lo es ni la deseo tener con v.m., mas cuando yo le hable, le diré todo claro como lo he hecho siempre $^{30}$.

Ella, siguiendo la estela de Santa Teresa, tuvo el convencimiento de que el

\footnotetext{
${ }^{25}$ A. de San Bartolomé, ob. cit., p. 505.

${ }^{26} \mathrm{El}$ autógrafo se conserva en el convento de las Carmelitas Descalzas de esta ciudad.

${ }^{27}$ A. de San Bartolomé, ob. cit., p. 341.

${ }^{28}$ A. Weber, ob. cit., p. 80.

${ }^{29}$ A. de San Bartolomé, ob. cit., p. 325.

${ }^{30}$ A. de San Bartolomé, ob. cit., pp. 927-928.
} 
relato de su vida espiritual poseía un sentido que trascendía los límites de la relación confesor-penitente.

Aunque puede aceptarse que Ana de San Bartolomé hablaba desde una ideología patriarcal (y acepta el poder de la jerarquía masculina de la Iglesia), hay que tener en cuenta un factor que le permitió superar un sentimiento paralizador de inferioridad: la creencia de que era heredera de la misión apostólica de Santa Teresa para ayudar a una Iglesia en crisis $^{31}$. Esta vertiente demuestra que estaba convencida de haber heredado la misión de Teresa y su poder carismático ${ }^{32}$. De esta manera, consideró su escritura como deber necesario y autorizado por Dios y su gran seguidora: la madre Teresa.

\section{LA ESTRATEGIA DEL ESTILO LLANO Y LA HUMILDE ARROGANCIA}

Sus manuscritos reflejan un estilo simple propio de una persona iletrada que desea, transcribiendo a Alison Weber ${ }^{33}$, «hablar a través de la escritura», con humilde naturalidad; en este sentido, notamos diferencias con la literatura teresiana. Teresa

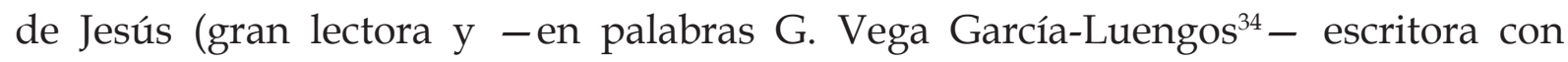
«irrestañable vocación literaria», aunque dijo en sus textos que rehuía escribir en un estilo alambicado y ornamentado), empleó estrategias retóricas complejas, cuyas imágenes sincréticas y renovaciones estilísticas han supuesto un reto para generaciones de lectores.

Por su parte, Ana no tenía tanta educación como su maestra, por eso, la llaneza y la sencillez de sus textos pudieron responder además, o sobre todo, a una hábil estrategia que le permitía verbalizar por escrito su vivencia de lo divino, ya que ella vivía por y para Cristo, porque él era quien la guiaba en su camino ${ }^{35}$.

Del mismo modo, su prosa sin adornos y llena de afectividad podía parecer ante el poder más fácil de controlar y menos ambiciosa, pues el tono espontáneo y natural no suponía una amenaza para sus superiores, sino todo lo contrario; por eso, no hay que olvidar que nuestra autora fue capaz de persuadir, ignorar e incluso desafiar

\footnotetext{
${ }^{31}$ A. Weber, ob. cit., p. 83.

${ }^{32}$ A. Weber, ob. cit., p. 84.

${ }^{33}$ A. Weber, ob. cit., p. 77.

${ }^{34}$ G. Vega García-Luengos, «Santa Teresa de Jesús ante la crítica literaria del siglo XX», Biblioteca Virtual Miguel de Cervantes, 2009. Disponible en: http://www.cervantesvirtual.com/obra-visor/santa-teresade-jesus-ante-la-critica-literaria-del-siglo-xx--0/html/2dc864d0-bc5a-439b-9f62-1ff8dad8da6e_7.html [consultado 25-01-2017].

35 Para un análisis más minucioso del estilo y los aspectos lingüísticos (fonéticos, morfológicos y sintácticos) de los escritos de Ana de San Bartolomé, consúltese el trabajo de J. J. Fernández, «Lenguaje y estilo en los escritos de Ana de San Bartolomé. El español popular de los siglos XVI y XVII», Creer y entender: Homenaje a Ramón Gonzálvez Ruiz, Toledo, Real Academia de Bellas Artes y Ciencias Históricas de Toledo, 2014, Vol. II, pp. 937-960.
} 
a la autoridad masculina ${ }^{36}$. Un ejemplo sería, como hemos visto, la sintaxis simple, sin ornamentos y fácil de interpretar que empleó con su confesor francés, Pierre de Bérulle, a quien, debido a las discrepancias entre ambos, le negó sus peticiones de escribir un ensayo espiritual. Incluso, en una carta de 1605, de manera sincera y directa, y excusándose por sus muchas labores, rechaza el deseo de Bérulle de escribir una relación sobre Santa Teresa:

En lo que v.m. me ha mandado de nuestra santa Madre, no he tenido lugar de nada por andar en el coro y refectorio y recreación, y queda después tan poco tiempo, que, en parlar con las hermanas que lo piden, se va. Y vaya enhorabuena, mi Padre, que yo me consuelo de ello por amor de Dios, mas yo lo haré en pudiendo ${ }^{37}$.

Así es como podemos comprender la humilde arrogancia de Ana, su piedad popular que cautivó a las élites de Francia, y su conciencia parcial de que los hombres sabios de la Iglesia habían limitado injustamente las aspiraciones intelectuales de ciertas mujeres $^{38}$. Ana de San Bartolomé supo aprovechar los conocimientos que había adquirido durante el tiempo que estuvo al lado de su maestra, para luego participar como miembro activo de la Iglesia y dejar así testimonio escrito de sus inquietudes, vivencias y, ante todo, su admiración por la gran escritora de la Edad de Oro que fue Teresa de Jesús.

\section{CONCLUSIÓN}

En conclusión, Ana de San Bartolomé supo emplear las estrategias discursivas apropiadas para rehuir del control y de la supervisión de la jerarquía eclesiástica, y así dar voz propia a sus escritos, siguiendo siempre la figura modélica de la Santa carmelita, quien, además de ser una guía ejemplar, se convirtió en autoridad espiritual: «Particularmente nuestra santa madre Teresa de Jesús, adonde hallaremos todo saber y buena enseñanza [...] aprendamos de ella» ${ }^{39}$.

\section{BibLiOgRAFÍA}

Alcalá, M., «Escribir desde los márgenes: la escritura como milagro en las Vidas de monjas», eHumanista: Journal of Iberian Studies, 29 (2015), pp. 639-659.

Alonso, D., La poesía de San Juan de la Cruz (desde esta ladera), Madrid, Aguilar, 1958.

\footnotetext{
${ }^{36}$ A. Weber, ob. cit., p. 91.

${ }^{37}$ A. de San Bartolomé, ob. cit., p. 831.

${ }^{38}$ A. Weber, ob. cit., p. 92.

${ }^{39}$ A. de San Bartolomé, ob. cit., p. 656.
} 
Amelang, J. S., «Autobiografías femeninas», en Historia de las mujeres en España y América, I. Morant (dir), Madrid, Cátedra, 2005, Vol. II, pp. 155-168.

BARANDA, N., Cortejo a lo prohibido. Lectoras y escritoras en la España moderna, Madrid, Arco/Libros, 2005.

Castillo, A., «Cartas desde el convento. Modelos epistolares femeninos en la España de la Contrarreforma», Cuadernos de Historia Moderna, 2014, Anejo XIII, pp. 141-168.

Cruz, S. J. de, Poesía, Domingo Ynduráin (ed.), Madrid, Cátedra, 2004.

FERNÁNDEZ, J. J., «Lenguaje y estilo en los escritos de Ana de San Bartolomé. El español popular de los siglos XVI y XVII», Creer y entender: Homenaje a Ramón Gonzálvez Ruiz, Toledo, Real Academia de Bellas Artes y Ciencias Históricas de Toledo, 2014, Vol. II, pp. 937-960.

FERrús, B., «Crea que andamos hechizadas la una con la otra. Mujeres en el entorno de Santa Teresa (cuerpos y almas)», Scriptura, 19/20 (2008), pp. 57-73.

Jesús, S. T. de, Obras completas, Efren de la Madre de Dios y Otger Steggink (eds.), Madrid, Biblioteca de Autores Cristianos, 2015.

Olivares, J. y Boyce, E. S, Tras el espejo la musa escribe. Lírica femenina de los Siglos de Oro, Madrid, Siglo XXI, 2012.

Prieto, A., La poesía española del siglo XVI, Madrid, Cátedra, 1998, Vol. II.

SAn Bartolomé, A. de, Obras completas, Julián Urkiza (ed.), Burgos, Monte Carmelo, 1999.

Vega García-Luengos, G., «Santa Teresa de Jesús ante la crítica literaria del siglo XX», Biblioteca Virtual Miguel de Cervantes, 2009. Disponible en: http://www. cervantesvirtual.com/obra-visor/santa-teresa-de-jesus-ante-la-critica-literaria-del-sigloxx--0/html/2dc864d0-bc5a-439b-9f62-1ff8dad8da6e_7.html [consultado 25-01-2017].

Weber, A., «El feminismo parcial de Ana de San Bartolomé», en L. Vollendorf, Literatura y feminismo en España (s. XV-XXI), Barcelona, Icaria, 2005, pp. 77-93. 